\title{
Virtual Lesion Extension: A Measure to Quantify the Effects of Bacterial Blight on Rice Leaf $\mathrm{CO}_{2}$ Exchange
}

\author{
Anne Elings, Walter A. H. Rossing, and Wopke van der Werf
}

First author: DLO Research Institute for Agrobiology and Soil Fertility, P.O. Box 14, 6700 AA Wageningen, the Netherlands; second and third authors: Department of Theoretical Production Ecology, Wageningen Agricultural University, P.O. Box 430, 6700 AK, the Netherlands. Accepted for publication 24 May 1999.

\begin{abstract}
Elings, A., Rossing, W. A. H., and van der Werf, W. 1999. Virtual lesion extension: A measure to quantify the effects of bacterial blight on rice leaf $\mathrm{CO}_{2}$ exchange. Phytopathology 89:789-795.

Virtual lesion extension was proposed as a measure to summarize the effects of foliar diseases with single spreading lesions on $\mathrm{CO}_{2}$-exchange parameters at the whole-leaf level. Visible lesion plus virtual lesion extension constitute a virtual lesion, in which $\mathrm{CO}_{2}$ exchange was postulated to be nil. Virtual lesion extension can be derived for each photosynthesis parameter from gas-exchange measurements. Using a leaf-shape function, one-dimensional lesion length was translated into two-dimensional

in rice leaves infected with Xanthomonas campestris pv. oryzae, the causal organism of rice bacterial blight. The model resulted in a virtual lesion extension of $1.1 \mathrm{~cm}$ for the gross $\mathrm{CO}_{2}$-exchange rate at light saturation, $-3.9 \mathrm{~cm}$ for dark respiration rate, and 0 for initial light use efficiency. Reduced light interception due to a visible lesion caused reductions in net $\mathrm{CO}_{2}$ assimilation, and small virtual lesion extensions only marginally reduced net $\mathrm{CO}_{2}$ assimilation further. The additional reduction was smaller in case of longer leaves. Measurement of net photosynthesis rate along a transect from the base to the tip of infected leaves indicated that the location on the leaf blade where net photosynthesis decreased from normal to nil was centered around the lesion tip.
\end{abstract} lesion area, and a relationship between visible and virtual severity can be established. The model was applied to measurements of leaf $\mathrm{CO}_{2}$ exchange
Additional keywords: Oriza sativa, visible severity.
Diseases interact in a variety of ways with crop growth processes, and these interactions can be studied at different levels of detail. Foliar diseases interfere with $\mathrm{CO}_{2}$ exchange in leaves, resulting in accelerated leaf senescence and/or reduced $\mathrm{CO}_{2}$-assimilation capacity. The causes of yield loss due to foliar diseases can studied by assessing the consequences of interactions at the whole-leaf level, using crop-growth simulation models (22).

Photosynthesis research on rice blast, caused by the fungus Pyricularia oryzae, resulted in the concept of a virtual lesion (2), which relates leaf photosynthesis to the area of a virtual lesion that is larger than the visible lesion. Parameter $\beta$ quantifies the constant ratio between virtual and visible lesion size. The $\beta$ model describes the simultaneous effects of the fungus on photosynthetic area and activity per unit of remaining photosynthetic area. By postulating that $\mathrm{CO}_{2}$ exchange is absent in the virtual lesion, virtual lesion size can be calculated based on gas-exchange measurements. The $\beta$ model has been used with other diseases as well. For instance, van der Werf et al. (25) characterized the effects of wheat powdery mildew (Erisyphe graminis) on the photosynthesis parameters of wheat leaves. The concept was elaborated for randomly distributed, small lesions that occupy $<20 \%$ of the total leaf area (12). A different approach is required for analysis of yield loss based on measurements at the whole-leaf level for diseases with single, spreading lesions, such as Xanthomonas campestris pv. oryzae, the causal organism of bacterial blight (BB) of rice (Oryza sativa L.). Relating leaf photosynthesis to the size of $\mathrm{BB}$ lesions requires a simple model that, in spite of its simplicity, provides an accurate quantitative description of the relationship.

$X$. campestris pv. oryzae enters rice leaves through wounds and hydathodes. The bacteria multiply in the epithem and enter the xylem vessels, where they spread and multiply further $(9,17)$. Ir-

Corresponding author: A. Elings; E-mail address: a.elings@ ab.dlo.nl

Publication no. P-1999-0707-01R

(C) 1999 The American Phytopathological Society regular, V-shaped lesions consisting of blighted and water-soaked leaf areas, form near the tip of the leaf blade and expand toward the base (Fig. 1, left side). A moving front of multiplying bacteria is located in the green leaf tissue bordering the lesion $(1,7,23)$. BB can cause up to $50 \%$ reduction in grain yield in severely infected crops (17). Highly fertilized crops seem to be especially prone to yield loss (22). Watanabe and Asaumi (29) measured a 1.7-fold increase in oxygen uptake after BB symptom appearance. In additional research, Watanabe et al. (30) observed that assimilates accumulate along veins, which turn yellow, and along borders of older lesions, indicating disrupted transport $(9,17)$. Philip and Devadath (19), remarkably, reported a positive effect of lesion development on the photosynthesis rate in the remaining green leaf tissue. Observations of the effects on photosynthesis by Jin et al. (10) were inconclusive, however, because measured photosynthesis rates were not expressed per unit of green leaf area. Disease-management tactics have been developed, using a crop-growth simulation model that accounts for the effects of $\mathrm{BB}$ on growth and production of rice (5) through incorporation of the major damage mechanisms, which Heong and Rossing (8) hypothesized to be effects on photosynthesis.

In our study, a theoretical framework and measurements are presented to relate whole-leaf photosynthesis to the fraction of leaf area covered by BB lesions. After exploratory measurements of net photosynthesis rate along a transect from the tip to the base of the leaf, we postulate the existence of virtual lesion extension and relate the extension to visible disease severity based on area, for which a leaf-shape function is developed. Effects on total leaf photosynthesis are related to visible disease severity.

\section{THEORY}

Outline. BB lesions usually develop from the tip to the base of the leaf and occupy the whole width of the leaf. Width is a leaf characteristic, and lesions may be characterized by their length. The effect of bacterial infection on leaf photosynthesis may extend be- 
yond the lesion into green leaf areas. We propose a virtual lesion extension (similar to the virtual lesion model of Bastiaans [2]) characterized only by length to summarize the effects of bacterial infection on whole-leaf $\mathrm{CO}_{2}$ exchange. We postulate that visible lesion and virtual lesion extension are photosynthetically inactive. The length of virtual lesion extension can be derived from photosynthesis measurements for each photosynthesis parameter. Because leaf photosynthesis rate depends on leaf area rather than length, a leaf-shape function that relates leaf length and width was developed to translate the length of the virtual lesion extension to its area, enabling an approach based on disease severity.

Concept and calculation of virtual lesion extension. BB lesion development on a rice leaf results in reduced radiation interception but also may result in reduced $\mathrm{CO}_{2}$-assimilation capacity in the remaining green leaf area. We postulate that the combined effect can be described by the length of the visible lesion plus an additional leaf section, which leads to a model of rice leaf infection by BB that consists of three leaf area categories (Fig. 1, left side): visible lesion, virtual lesion extension (2) from lesion front into green leaf area, and remaining green, healthy leaf area. By definition, the visible lesion and virtual lesion extension do not photosynthesize, whereas the healthy part of the leaf has gas-exchange parameters that are the same as those for completely healthy leaves. This is a intentional simplification of the more complex reality: it is likely that bacterial concentrations and gas-exchange parameters gradually change in the leaf zone between the necrotic lesion and green leaf base. The length of the virtual lesion extension can be determined by combining the theoretical model with gas-exchange measurements on healthy and infected leaves.

Rates of leaf photosynthesis usually are derived from $\mathrm{CO}_{2}$ gasexchange measurements of a leaf section inside a small chamber. The shape of the leaf section may be approximated by a trapezoid (Fig. 1, right side). Within the leaf section, three constituent trapezoids approximate the shape of the visible lesion, virtual lesion exten-

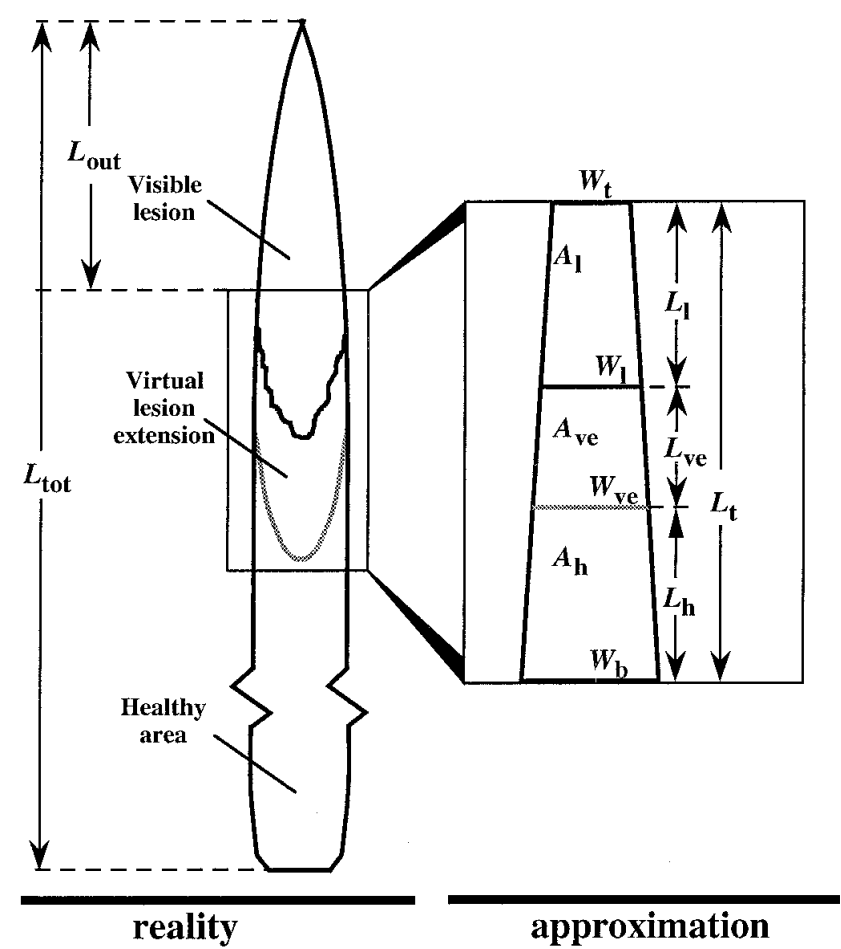

Fig. 1. Schematic representation of a rice leaf with a bacterial blight lesion, consisting of a visible lesion, virtual lesion extension, and portion of remaining healthy leaf tissue (left). Photosynthesis measurements were obtained with a $\mathrm{CO}_{2}$-analyzer leaf chamber clamped over a section of leaf (rectangle to left). Areas in the chamber are approximated by trapezoids (right). Variables are described in text. sion, and healthy area, leading to formulae for leaf areas within the chamber (not the entire leaf blade):

$$
\begin{array}{ll}
\text { visible lesion: } & A_{1}=L_{\mathrm{l}}\left(W_{t}+W_{\mathrm{l}}\right) / 2 \\
\text { virtual lesion extension: } & A_{v e}=L_{v e}\left(W_{1}+W_{v e}\right) / 2 \\
\text { healthy tissue: } & A_{h}=L_{h}\left(W_{v e}+W_{b}\right) / 2
\end{array}
$$

Parameters $A_{l}, A_{v e}$, and $A_{h}$ (square meters) are the areas of the trapezoids that approximate the areas of visible lesion, virtual lesion extension, and healthy tissue, respectively. $W_{t}$ (meters) is the top width of the trapezoid that approximates visible lesion area. $W_{1}$ (meters) is the bottom width of the trapezoid that approximates visible lesion area, which is equal to the top width of the trapezoid that approximates the virtual lesion extension area. $W_{v e}$ (meters) is the bottom width of the trapezoid that approximates the virtual lesion extension area, which is equal to the top width of the trapezoid that approximates the healthy area. $W_{b}$ (meters) is the bottom width of the trapezoid that approximates the healthy area. $L_{\mathrm{l}}$, $L_{v e}$, and $L_{h}$ (meters) are the heights of the trapezoids that approximate the areas of visible lesion, virtual lesion extension, and healthy tissue, respectively. For congruency, $W_{v e}$ can be expressed in terms of $W_{t}, W_{b}, L_{\mathrm{l}}, L_{v e}$, and $L_{t}$ :

$$
W_{v e}=W_{b}-\left(W_{b}-W_{t}\right) \times\left[1-\left(L_{1}+L_{v e}\right) / L_{t}\right]
$$

Parameter $L_{t}$ (meters) is the length of the trapezoid describing the leaf section inside the chamber.

The $\mathrm{CO}_{2}$-exchange rate of the measured leaf section, based on the definition of the virtual lesion model, is entirely due to gas exchange in the healthy area:

$$
P_{t} \times A_{t}=P_{h} \times A_{h}
$$

Parameters $P_{t}$ and $P_{h}$ (grams of $\mathrm{CO}_{2}$ per square meter per second) are average photosynthesis rates per unit of total measured leaf section and healthy leaf area, respectively. $A_{t}$ (square meters) is the area of the trapezoid that approximates the total measured area. Equation 4 is derived by substituting equations $1 \mathrm{c}$ and 2 in equation 3:

$$
P_{t} \times A_{t}=P_{h} \times\left(W_{b}-\left[\left(W_{b}-W_{t}\right) / 2\right] \times\left\{1-\left[\left(L_{1}+L_{v e}\right) / L_{t}\right]\right\} \times\left(L_{t}-L_{1}+L_{v e}\right)\right)
$$

Using equation 4 , the unknown length $\left(L_{\mathrm{ve}}\right)$ of the virtual lesion extension can be solved. $P_{t} \times A_{t}$ and $P_{h}$ result from photosynthesis measurements of infected and noninfected leaves, respectively. $W_{b}, W_{t}, L_{\mathrm{l}}$, and $L_{t}$ can be measured on infected leaves. We estimated visible lesion length $\left(L_{1}\right)$ by visual replacement of the $\mathrm{V}$-shaped lesion front with a flat front while keeping lesion area constant. Width was determined at the resulting location of the flat lesion margin (Fig. 1, right side).

Relationship between lesion length and disease severity. Because disease severity is normally not quantified on the basis of lesion length, but as the leaf area fraction affected, a relationship between lesion length and area was needed. Length and area of a leaf segment can be related with a shape function, $S$. Suppose that at any position along the transect of a leaf blade, $W^{\prime}$ is defined as leaf width relative to maximum leaf width, and $L^{\prime}$ is defined as distance to leaf tip relative to total leaf length, then $S$, relating $W^{\prime}$ to $L^{\prime}$, describes the shape and, therefore area, of the leaf blade.

Shape function $S$ was established based on measurements taken from a set of rice leaves. From experimental fields at the Philippine Rice Research Institute (Muñoz, Nueva Ecija), 10 leaves of cvs. IR64 and PSBRc14 were collected randomly and photocopied. At least 10 combinations of length and width were measured per leaf. Measured positions were spaced equally over the length of the leaf, and extra points were placed as far as required by the curvature of the leaf edge. Care was taken to include the combina- 
tion with maximum leaf width. Double exponential function $S$ described an adequate relationship between $W^{\prime}$ and $L^{\prime}$ :

$$
W^{\prime}=S\left(L^{\prime}\right)=c \times\left(1-e^{-a_{1}\left[L_{0}+\left(1-L^{\prime}\right)\right]}\right) \times\left(1-e^{-a_{2} L^{\prime}}\right)
$$

Parameters $a_{1}$ and $a_{2}$ indicate slope, and $c$ indicates scale. The value of $L^{\prime}$ is 0 at the leaf base and 1 at the leaf tip. $L_{0}$ defines the intersection of $S$ and the x-axis. Integration of equation 5 over $L^{\prime}$ gives the area of the leaf section between leaf tip and the position on the leaf at relative distance $L^{\prime}$. Equation 5 was fitted to the data by statistical software procedure NLIN/DUD (SAS Institute, Cary, NC).

Finally, visible disease severity $(x)$ and virtual disease severity (y) are calculated as

$$
\begin{gathered}
x=\left(A_{\mathrm{out}}+A_{1}\right) / A_{\mathrm{tot}}=\int_{0}^{\left(L_{\mathrm{out}}+L_{1}\right) / L_{\mathrm{tot}}} S d\left(L^{\prime}\right) / \int_{0}^{1} S d\left(L^{\prime}\right) \\
y=\left(A_{\mathrm{out}}+A_{1}+A_{v e}\right) / A_{\mathrm{tot}}=\int_{0}^{\left(L_{\mathrm{out}}+L_{1}+L_{v e}\right) / L_{\mathrm{tot}}} S d\left(L^{\prime}\right) / \int_{0}^{1} S d\left(L^{\prime}\right)
\end{gathered}
$$

Parameters $A_{\text {out }}$ and $A_{\text {tot }}$ (square meters) are the areas of visible lesion outside the measurement chamber and entire leaf blade, respectively, and $L_{\text {out }}$ and $L_{\text {tot }}$ (meters) are the respective lengths of visible lesion outside the measurement and entire leaf blade (Fig. 1, left side).

Photosynthesis. The photosynthesis light-response curve of a leaf with visible severity $(x)$ is described by a negative exponential relationship (6):

$$
P_{x}=P_{\max , \mathrm{x}}\left(1-e^{\left.-\varepsilon_{x} l / P_{\max , x}\right)}-R_{d, x}\right.
$$

Parameter $P_{x}$ at any light level and $P_{\max , \mathrm{x}}$ at light saturation (grams of $\mathrm{CO}_{2}$ per square meter per second) are net photosynthesis rate and gross leaf photosynthesis rate at light saturation, respectively. $\varepsilon_{x}$ (grams of $\mathrm{CO}_{2}$ per square meter per second/joules per square meter per second) is initial radiation use efficiency. $R_{d, x}$ (grams of $\mathrm{CO}_{2}$ per square meter per second) is dark respiration. $I$ (joules per square meter per second) is absorbed photosynthetically active radiation (PAR). All parameter values in equation 7 depend on visible severity, which is indicated by subscript $x$. Because by definition no gas exchange occurs in the visible lesion and virtual lesion extension, gas-exchange parameter values for an infected leaf can be calculated as

$$
Q_{x}=(1-y) Q_{0}
$$

Parameter $Q_{x}$ represents $P_{\max , x}, \varepsilon_{x}$, or $R_{d, x}$ of a leaf with visible severity $(x)$, and $Q_{0}$ represents the respective parameters for a healthy leaf. Because photosynthesis parameters do not necessarily depend on virtual severity, $y$ may have a different value for $P_{\max , x}, \varepsilon_{x}$, and $R_{d, x}$.

\section{MEASUREMENTS}

Transect. Photosynthesis measurements of BB-infected leaves were performed at the International Rice Research Institute (Los Baños, Philippines). Seedlings of rice cv. IR64 were transplanted on 23 February 1993 (36 days after sowing) into 24 clay pots, each containing 3 plants. The pots $(25 \mathrm{~cm}$ in diameter and filled with mahaas clay) were placed in a screenhouse and irrigated daily. Urea (45\% ammonium sulfate [weight basis]) was applied at a rate of $500 \mathrm{mg} /$ pot at transplanting and maximum tillering (1 April 1993). Temperatures in the screenhouse varied between 20 and $35^{\circ} \mathrm{C}$.

Fully developed leaves were clip-inoculated on 1 April, as described by Kauffman et al. (13), with BB race 2, which is endemic to the Philippines and to which IR64 is moderately susceptible (14). Plants were enclosed in jute sacks kept moist by regular spraying for up to 5 days after inoculation (DAI). During the first 2 days, plants were sprayed with water every 30 min during daylight. Watersoaked areas on leaf tips appeared by 5 DAI.

Net photosynthesis rate was measured with a portable leaf chamber analyzer (LCA-2, Analytical Development Company, Hoddesdon, England). Four halogen lamps (HPI-T, Philips, Eindhoven, the Neth- erlands) were used as additional light sources. A water bath with a glass frame was installed just below the lamps to intercept heat radiation (3). Plants were allowed to adapt for $30 \mathrm{~min}$ before measurements were taken; all measurements were taken before 11:30 a.m. Ambient air was collected on the screenhouse roof at a rate of $\approx 350 \mathrm{ml} \mathrm{min}$. . Air temperature in the leaf chamber varied from 30 to $35^{\circ} \mathrm{C}$, and relative humidity varied from 35 to $50 \%$. Incident PAR was stable for a series of measurements from one leaf but varied between measurements from 25 to $150 \mathrm{~J} \mathrm{~m}^{-2} \mathrm{~s}^{-1}$ due to cloudy weather conditions and the shading effect of the screenhouse roof. Rates of photosynthesis did not increase at irradiation levels higher than $35 \mathrm{~J} \mathrm{~m}^{-2} \mathrm{~s}^{-1}$, reflecting adaptation of leaves to the low light intensity (21) beneath the roof of the screenhouse. Approximately six measurements per leaf were taken at different locations on each leaf blade to measure various combinations of blighted, water-soaked, and green leaf areas. The leaf chamber included $5.6 \mathrm{~cm}$ of leaf length and total leaf width. After photosynthesis was measured, outlines of total, dead, and water-soaked leaf areas were traced on a transparent sheet, and areas were determined by overlaying grids (square millimeters). Visible disease severity was defined as the proportion of blighted plus watersoaked leaf area.

Photosynthesis rates reached their highest values at the proximate, healthy parts of leaf blades. Observations of leaves for which a stable, high photosynthesis rate could not be established for at least two locations on the proximate part of the leaf blade were excluded from analysis. Relative net $\mathrm{CO}_{2}$-assimilation rate per individual leaf $\left(P_{\text {ind }}^{\prime}\right)$ was calculated for each leaf section as the actual photosynthesis rate relative to the rate of photosynthesis at the base of the leaf. $P_{\text {ind }}^{\prime}$ of a leaf section was related to distance, $d$ (centimeters), from the center of the measured leaf section and the V-shaped lesion tip by a logistic function:

$$
P_{\text {ind }}^{\prime}=1 /\left(1+e^{-k\left(d-d_{50}\right)}\right)
$$

Parameter $k$ determines the slope of the curve. $P^{\prime}{ }_{\text {ind }}$ reaches $50 \%$ of its maximum value at $d_{50}$ (centimeters) from the lesion tip. $\mathrm{Pa}$ rameter values were determined by fitting equation 9 .

Length of virtual lesion extension and photosynthesis parameters. Experiments were performed at the DLO Research Institute for Agrobiology and Soil Fertility (Wageningen, the Netherlands) in 1993 and 1994. Rice seeds were germinated in moist petri dishes incubated in a chamber (Heraeus Kulzer GmbH, Wehrheim, Germany) at a day/night temperature regime of $23 / 19^{\circ} \mathrm{C}$ and $90 \%$ relative humidity (RH, 1993) or kept at ambient room conditions (1994). In total, three series of plants were used: one in 1993 and two in 1994. Germinated seeds were transplanted on 3 June 1993 and 17 and 24 May 1994 into 10-liter plastic buckets filled with black sand with low organic matter content. Ample water was supplied, and buckets were drained weekly to minimize soil acidification. Hoagland nutrient solution and urea (45\% ammonium sulfate [weight basis]) were supplied after draining to maintain high soil fertility. Buckets were placed in a glasshouse at a day/night temperature regime of $30 / 20^{\circ} \mathrm{C}$ and $90 \% \mathrm{RH}$. Natural daylight conditions in 1993 were sufficient for normal crop growth, whereas in 1994 additional artificial illumination was supplied.

Race $2 X$. campestris pv. oryzae bacteria were revived from lyophilized stock and used to clip-inoculate just fully expanded leaves on 15 July 1993 and 27 June and 4 July 1994. The control treatment consisted of clipping with scissors dipped in water.

The first BB symptoms appeared 5 to 7 DAI. Leaf photosynthesis was measured on 8, 13, 14, and 15 DAI in 1993 and 7 to 11 DAI in 1994 with an assembly containing four leaf chambers (10 cm wide) that operated simultaneously (16). Five to six leaves were inserted per chamber. Net $\mathrm{CO}_{2}$ assimilation was measured at $25^{\circ} \mathrm{C}$ at absorbed PAR levels of $\approx 25,80,120,180,240$, and $0 \mathrm{~J} \mathrm{~m}^{-2} \mathrm{~s}^{-1}$ (1993) and 20, 70, 105, 155, and 210 and $0 \mathrm{~J} \mathrm{~m}^{-2} \mathrm{~s}^{-1}$ (1994). The time interval between light steps was 30 to $45 \mathrm{~min}$ to obtain stable $\mathrm{CO}_{2}$-exchange readings. Area, specific leaf weight, 
and leaf nitrogen content (LNC; Dumas method) were determined after photosynthesis measurements of diseased and healthy tissues inside and outside the leaf chamber. Outlines of total, dead, and watersoaked leaf areas inside and outside the leaf chamber were traced on a transparent sheet for each leaf.

Equation 4 was used to estimate aggregated $L_{v e}$ for all leaves inside the chamber. To obtain the average $L_{v e}$ per leaf, the aggregated $L_{v e}$ was divided by the number of virtual lesion exten-

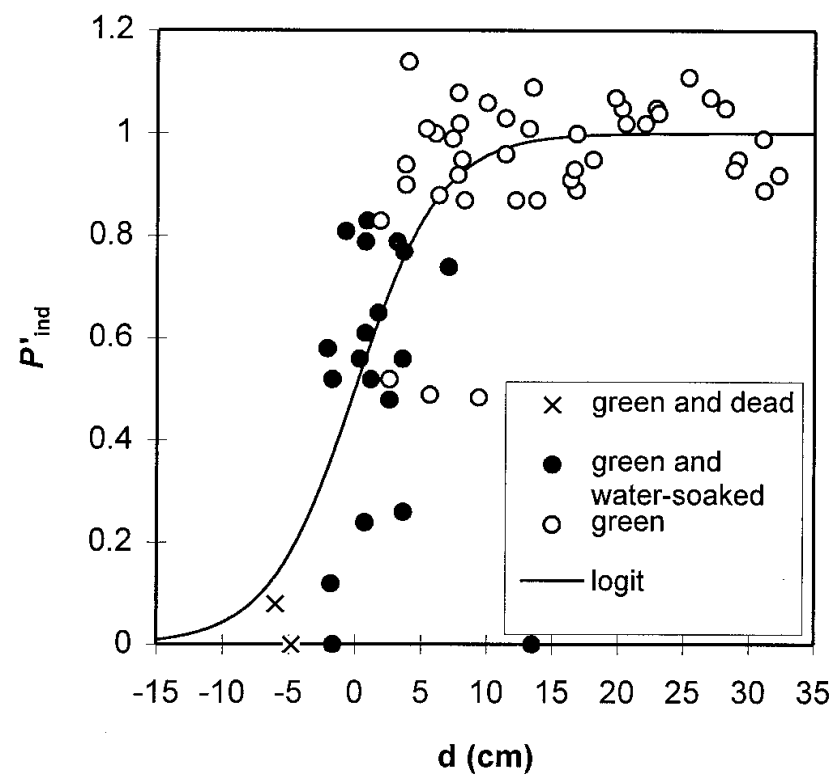

Fig. 2. Relationship between relative net rate of photosynthesis $\left(P^{\prime}{ }_{\text {ind }}\right)$ and distance $(d)$ from the center of the measured leaf section to the V-shaped lesion tip. Leaf sections consisted of green, green and water-soaked, and green and dead leaf areas. Least squares estimates for the logistic function: slope of curve, $k=0.31$ ( $\mathrm{SE}=0.0580)$; distance from lesion at which $P_{\text {ind }}^{\prime}$ reaches $50 \%$ maximum value, $d_{50}=0.004(\mathrm{SE}=0.58) ; r^{2}=0.64$; square root of MSE (mean standard error) $=0.18 ; n=62$.

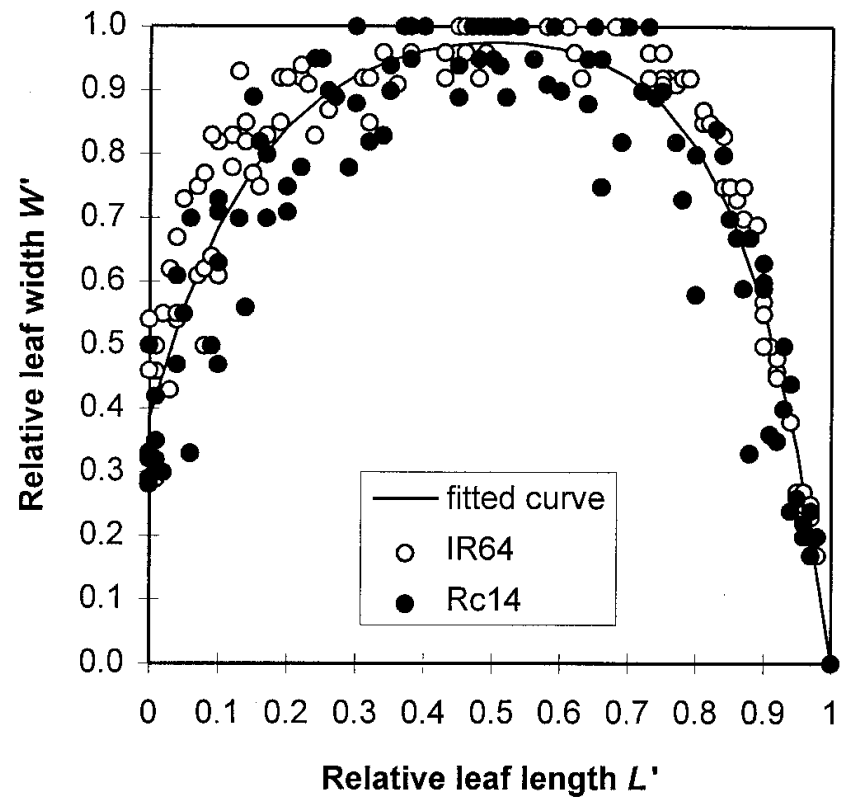

Fig. 3. Relationship between leaf width $\left(W^{\prime}\right)$ and leaf length $\left(L^{\prime}\right)$, both relative to their maximum values, for individual leaves of rice cvs. IR64 and PSBRc14. $L^{\prime}$ is 0 at leaf base and 1 at leaf tip. Drawn line represents double exponential equation (equation 5) fitted to pooled data. Least squares estimates: scaling parameter, $c=1.02(\mathrm{SE}=0.02)$; intersection of $S$ and $\mathrm{x}$ axis, $L_{0}=0.074(\mathrm{SE}=$ $0.009)$; slope parameters, $a_{1}=6.4(\mathrm{SE}=0.6)$ and $a_{2}=8.0(\mathrm{SE}=0.4) ; r^{2}=$ 0.94 ; square root of MSE (mean standard error) $=0.076$. sions inside the chamber. The averaging procedure required that the $L_{v e}$ of an individual leaf be independent of the total length of the lesion (inside and outside the chamber). Because total lesion length had not been measured, the entire data set was used to test whether $L_{v e}$ was constant in relation to within-chamber visible lesion length $\left(L_{1}\right)$. This was established by testing the significance of the slope of the linear regression of $L_{v e}$ on $L_{1}$.

The parameter values of the photosynthesis light-response curve per set of five to six measured leaves were determined by fitting equation 7 to the data, using the nonlinear regression option of the Genstat statistical package (Genstat, Lawes Agricultural Trust, Hertfordshire, England). To eliminate the confounding effect of LNC on $P_{\max }$, measured values were standardized to the pooled average LNC for green and water-soaked leaf tissue in all measured leaves: $P_{\max }=-6.5+32.4 \times \mathrm{LNC}(18,26)$. The pooled LNC was $1.137 \mathrm{~g} \mathrm{~m}^{-2}$ (standard deviation $[\mathrm{SD}]=0.150, n=40$ ), which is equivalent to $42.4 \mathrm{mg} \mathrm{g}^{-1}$. Parameters $\varepsilon$ and $R_{d}$ are not influenced by LNC (4). Means of $P_{\max }, \varepsilon$, and $R_{d}$ values of unclipped leaves and leaves
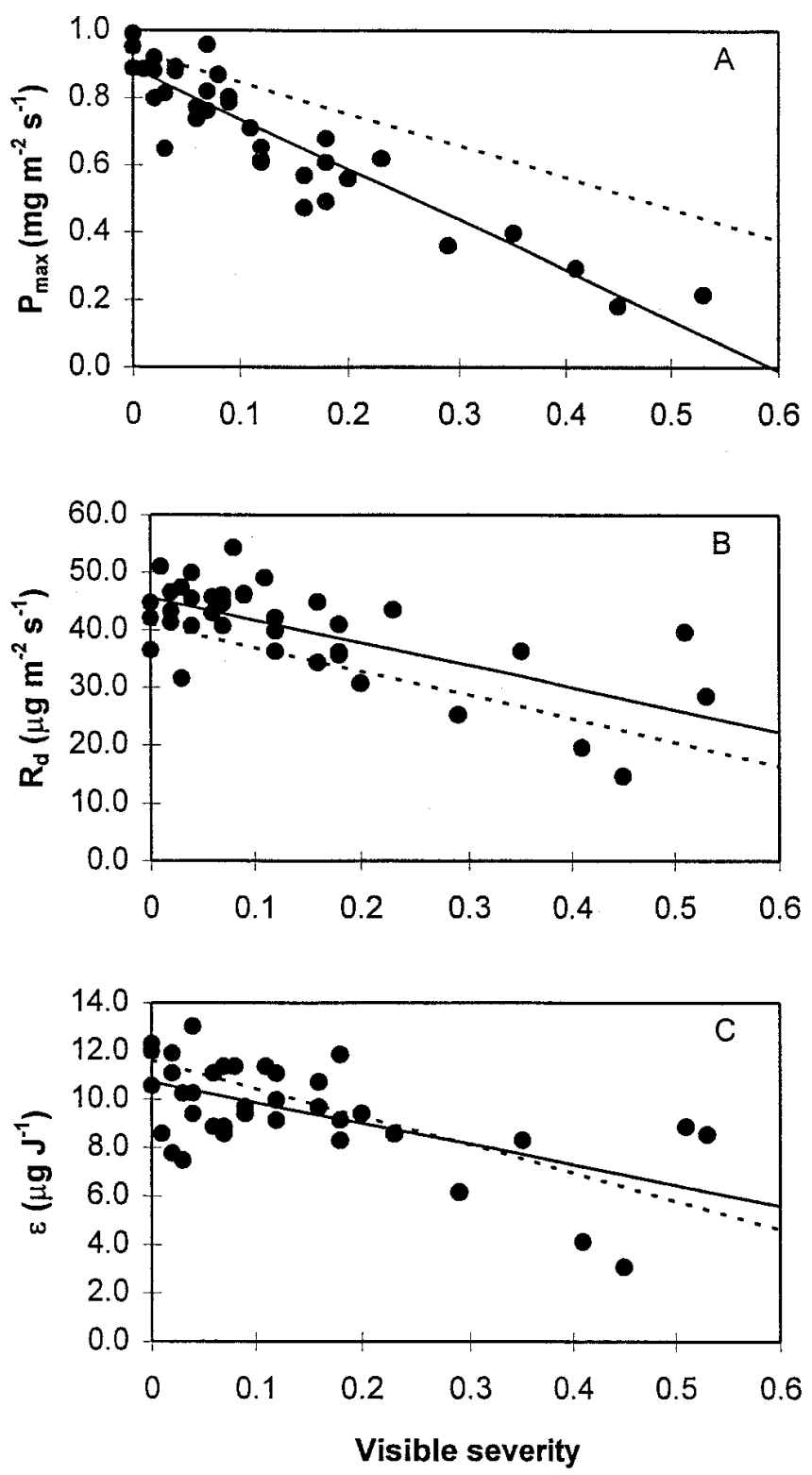

Fig. 4. Fitted linear relationships (solid lines) between visible severity and $\mathbf{A}$, gross assimilation rate at light saturation (gross leaf photosynthesis rate, $\left.P_{\max } ; r^{2}=0.86\right) ; \mathbf{B}$, dark respiration $\left(R_{d} ; r^{2}=0.43\right)$; and $\mathbf{C}$, initial light use efficiency $\left(\varepsilon ; r^{2}=0.34\right)$. Dashed lines indicate expected relationships if changes in parameter values are due only to increases in visible lesion area. 
clipped with clean scissors (controls) were compared by $t$ test to assess the effect of clipping on leaf photosynthesis.

To illustrate the effects of $\mathrm{BB}$ infection at different radiation levels on net $\mathrm{CO}_{2}$-assimilation rate, $P_{x}$ was calculated for visible severities $(x)$ of $0.25,0.50$, and 0.75 , for 20 - and 50 -cm-long leaves (maximum $1.5 \mathrm{~cm}$ wide).

\section{RESULTS}

Transect measurements of leaf photosynthesis. Observations of green plus water-soaked areas were made in 5-cm-long regions on both sides of the lesion tip, yielding $P^{\prime}$ ind values between 0 and 0.83 (Fig. 2). Two observations of dead plus water-soaked leaf areas were made, yielding $P_{\text {ind }}^{\prime}$ values of 0 and 0.08 , respectively. Fitted equation 9 was characterized by estimated $k$ and $d_{50}$ values of 0.31 (standard error $[\mathrm{SE}]=0.058)$ and $0.004 \mathrm{~cm}(\mathrm{SE}=0.58)$, respectively. The estimated value for $d_{50}$ did not differ from $0(P>0.10)$.

Leaf-shape function. Equation 5 provided an adequate description of leaf shape for both rice cultivars (Fig. 3). Parameters estimates were based on combined values for the two cultivars, because calculations for each cultivar separately did not differ significantly $(P<0.05)$. Parameter values for equation 5 were $a_{1}=6.4(\mathrm{SE}=0.6)$, $a_{2}=8.0(\mathrm{SE}=0.4), c=1.02(\mathrm{SE}=0.02)$, and $L_{0}=0.074(\mathrm{SE}=0.009)$. The integrated form of equation 5 was

$\int_{0}^{L^{\prime}} S d\left(L^{\prime}\right)=-0.127+1.02 L^{\prime}+1.128 e^{-8 L^{\prime}}+e^{6.4 L^{\prime}}\left(-0.000165-0.638 e^{-6.874-8 L^{\prime}}\right)$

Integration over total relative leaf length $\left(L^{\prime}=1\right)$ yielded a value of 0.794 . The area of a single rice leaf can be estimated by the multiple product of $L_{\text {tot }}, W_{\text {tot }}$, and 0.794 .

Leaf photosynthesis light response and virtual severity. Means of $P_{\max }, \varepsilon$, and $R_{d}$ for unclipped and control treatments did not differ significantly $(P<0.05)$. As a result, the effect of clipping on leaf photosynthesis was disregarded. Means of $\mathrm{P}_{\max }$ for healthy unclipped leaves for the three measurement series were $9.18,9.56$, and $8.93 \times$
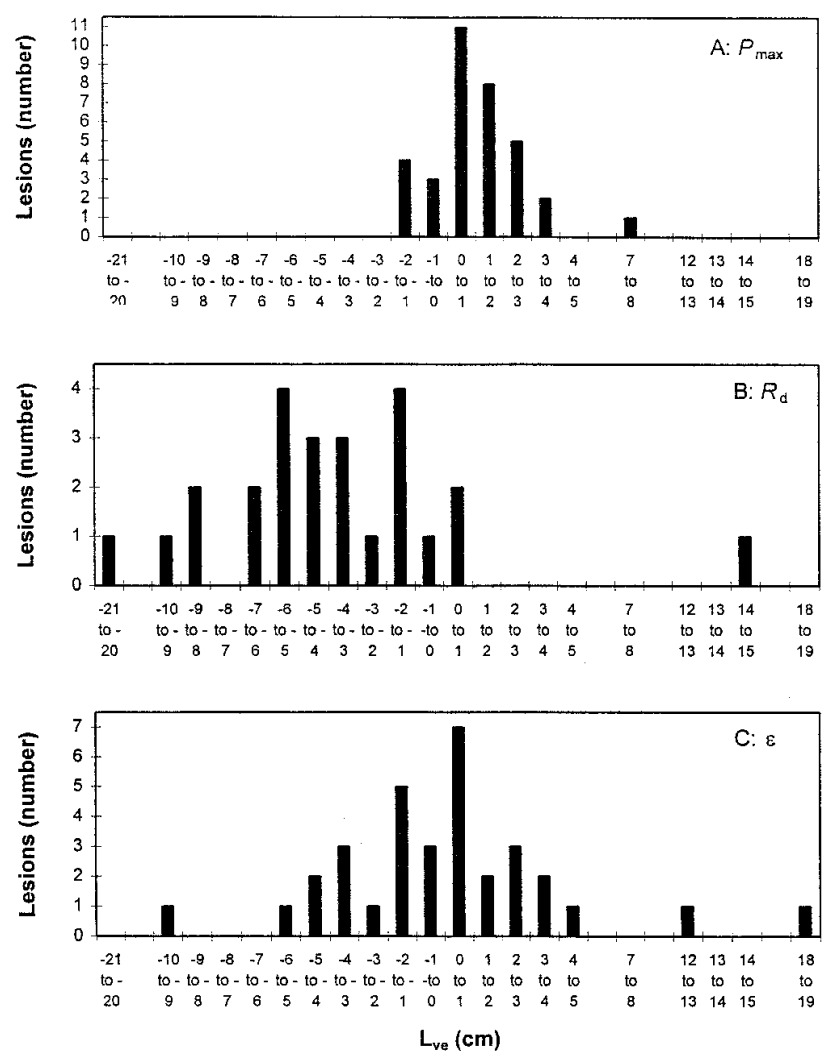

Fig. 5. Frequency distributions of estimated length of virtual lesion extension, $L_{v e}$ (centimeters), for $\mathbf{A}, P_{\max }$, gross leaf photosynthesis rate; $\mathbf{B}, R_{d}$, dark respiration; and $\mathbf{C}, \varepsilon$, initial light use efficiency.
$10^{-4} \mathrm{~g}$ of $\mathrm{CO}_{2} \mathrm{~m}^{-2} \mathrm{~s}^{-1}$, respectively; means of $R_{d}$ were $3.83,4.42$, and $4.74 \times 10^{-5} \mathrm{~g}^{-1} \mathrm{CO}_{2} \mathrm{~m}^{-2} \mathrm{~s}^{-1}$, respectively; and means of $\varepsilon$ were $1.24,1.27$, and $1.05 \times 10^{-5} \mathrm{~g} \mathrm{~J}^{-1}$, respectively. Series means differed significantly $(P<0.05)$; however, such differences could be ignored because parameter values were taken relative to unclipped leaves of the same series. The overall mean for $P_{\max }$ was $9.22 \times$ $10^{-4} \mathrm{~g}$ of $\mathrm{CO}_{2} \mathrm{~m}^{-2} \mathrm{~s}^{-1}\left(=33.2 \mathrm{~kg}\right.$ of $\left.\mathrm{CO}_{2} \mathrm{ha}^{-1} \mathrm{~h}^{-1}\right)$; the overall mean for $R_{d}$ was $4.28 \times 10^{-5} \mathrm{~g}$ of $\mathrm{CO}_{2} \mathrm{~m}^{-2} \mathrm{~s}^{-1}\left(=1.54 \mathrm{~kg}\right.$ of $\left.\mathrm{CO}_{2} \mathrm{ha}^{-1} \mathrm{~h}^{-1}\right)$;

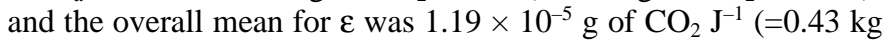
of $\left.\mathrm{CO}_{2} \mathrm{ha}^{-1} \mathrm{~h}^{-1} /\left(\mathrm{J} \mathrm{m}^{-2} \mathrm{~s}^{-1}\right)\right)$. These averages are realistic values for rice with an average LNC concentration of $42.4 \mathrm{mg} \mathrm{g}^{-1}$ and grown at a day/night temperature regime of $30 / 20^{\circ} \mathrm{C}(15)$.

Reduction of $P_{\max }$ was larger than could be explained by visible lesion area in the measurement chamber (Fig. 4a), whereas reduction of $R_{d}$ was smaller than could be explained by visible lesion area (Fig. 4b). Reduction of $\varepsilon$ seemed proportional to the increase in visible lesion area (Fig. 4c).

Linear regression of $L_{v e}$ on $L_{1}$ did not indicate significant relationships between $P_{\max }(P=0.59), R_{d}(P=0.16)$, and $\varepsilon(P=0.26)$. The length of virtual lesion extension, therefore, was not linearly related to the length of visible lesion in the measurement chamber for these three photosynthesis parameters. Visual inspection of the data also led to the conclusion that nonlinear relationships are unlikely.

Mean $L_{v e}$ for $P_{\max }$ and $\varepsilon$ were $1.06 \mathrm{~cm}(\mathrm{SE}=0.28 \mathrm{~cm})$ and $0.22 \mathrm{~cm}$ $(\mathrm{SE}=0.86 \mathrm{~cm})$, respectively (Fig. 5$). L_{v e}$ for $R_{d}$ was $-3.94 \mathrm{~cm}(\mathrm{SE}=$ $0.99 \mathrm{~cm}$ ). Effects on $P_{\max }$ and $R_{d}$ were significant $(P<0.05)$, whereas the effect on $\varepsilon$ was not. Under the null hypothesis of no effect, $\mathrm{BB}$ results in a virtual lesion extension of $1.1 \mathrm{~cm}$ for $P_{\max }$ and -3.9 cm (i.e., lesion 'shrinkage' of $3.9 \mathrm{~cm}$ ) for $R_{d}$.

Relationships between visible severity, $x$, and virtual severity, $y$, depend on leaf length. A specific virtual lesion extension, $L_{v e}$, for a large leaf represents a smaller fraction of the total leaf area than for a small leaf. As a consequence, the difference between $x$ and $y$ will be smaller for longer leaves. Figure 6 illustrates the difference by comparing visible and virtual severities for $P_{\max }$ and $R_{d}$. Because of the larger but negative value of $L_{v e}$ for $R_{d}$, the relationship between visible and virtual severities for $R_{d}$ deviated more from the 1:1 line than for $P_{\max , \mathrm{x}}$ but is situated on the opposite side.

Figure 7 provides the calculated photosynthesis light-response curves (equation 7) with mean parameter values for both visible and virtual severities, as determined for completely healthy leaves that were 20 and $50 \mathrm{~cm}$ long and visible $\mathrm{BB}$ severities

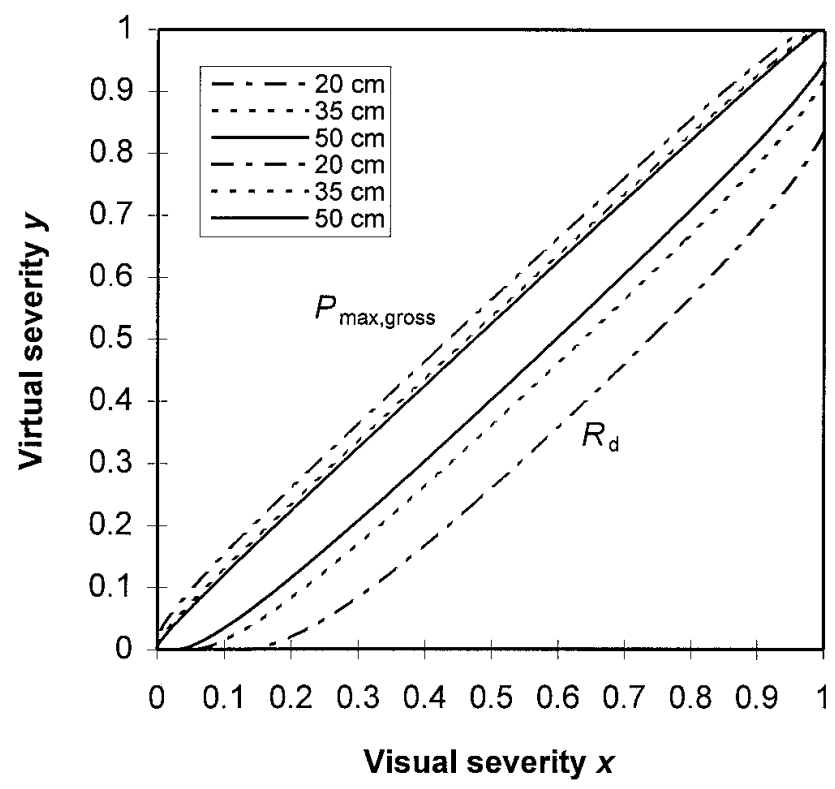

Fig. 6. Virtual severity $(y)$ for gross leaf photosynthesis rate $\left(P_{\max }\right.$, upper three lines) and dark respiration $\left(R_{d}\right.$, lower three lines) in relation to visible severity $(x)$ for leaf lengths of 20,35 and $50 \mathrm{~cm}$. 
of $0.25,0.50$, and 0.75 , respectively. Photosynthesis light-response curves calculated on the basis of visible severity $(x)$ represent the decrease in $P_{x}$ due to reduction in green leaf area. The decrease in $P_{x}$ increases with increasing radiation but is not influenced by leaf length. Photosynthesis light-response curves calculated on the basis of virtual severity $(y)$ represent the decrease in $P_{x}$ due to reduction in green leaf area and radiation use efficiency in the remaining photosynthetically active green leaf area (11). The decrease in $P_{x}$ was slightly larger than could be explained by loss of green leaf area. $P_{x}$ at a specific visible severity decreased less in large leaves than in small leaves: $P_{x}$ at high radiation levels calculated on the basis of virtual severities for 50-cm-long leaves was 0.025 to $0.027 \mathrm{mg}$ of $\mathrm{CO}_{2} \mathrm{~m}^{-2} \mathrm{~s}^{-1}$ less than for corresponding visible severities, whereas corresponding values for 20 -cm-long leaves were 0.051 to $0.055 \mathrm{mg}$ of $\mathrm{CO}_{2} \mathrm{~m}^{-2} \mathrm{~s}^{-1}$ less.

\section{DISCUSSION}

Virtual lesion extensions for $P_{\max }$ and $R_{d}$ caused rates of net leaf $\mathrm{CO}_{2}$ exchange $\left(P_{x}\right)$ at high radiaton levels for 50- and 20-cm-long leaves to be, at most, 0.027 and $0.055 \mathrm{mg}$ of $\mathrm{CO}_{2} \mathrm{~m}^{-2} \mathrm{~s}^{-1}$ less, respectively, than rates for leaves with corresponding visible severities. These measurements agree with the exploratory measurements on leaf transects in which net photosynthesis rate decreased from maximum at the base of the leaf blade to 0 in the necrotic portion of the $\mathrm{BB}$ lesion at the leaf tip. The $d_{50}$ value was not significantly different from 0 , indicating the decrease in net photosynthesis is centered around the V-shaped tip of the visual lesion (Fig. 2). Johnson (11) distinguished two major categories of disease effects on crop growth: reduction in interception of solar radiation by green leaf area and reduction in radiation use efficiency. The small impact of $\mathrm{BB}$ on $\mathrm{CO}_{2}$ exchange in green leaf areas implies that the effect of $\mathrm{BB}$ on crop yield may be investigated by

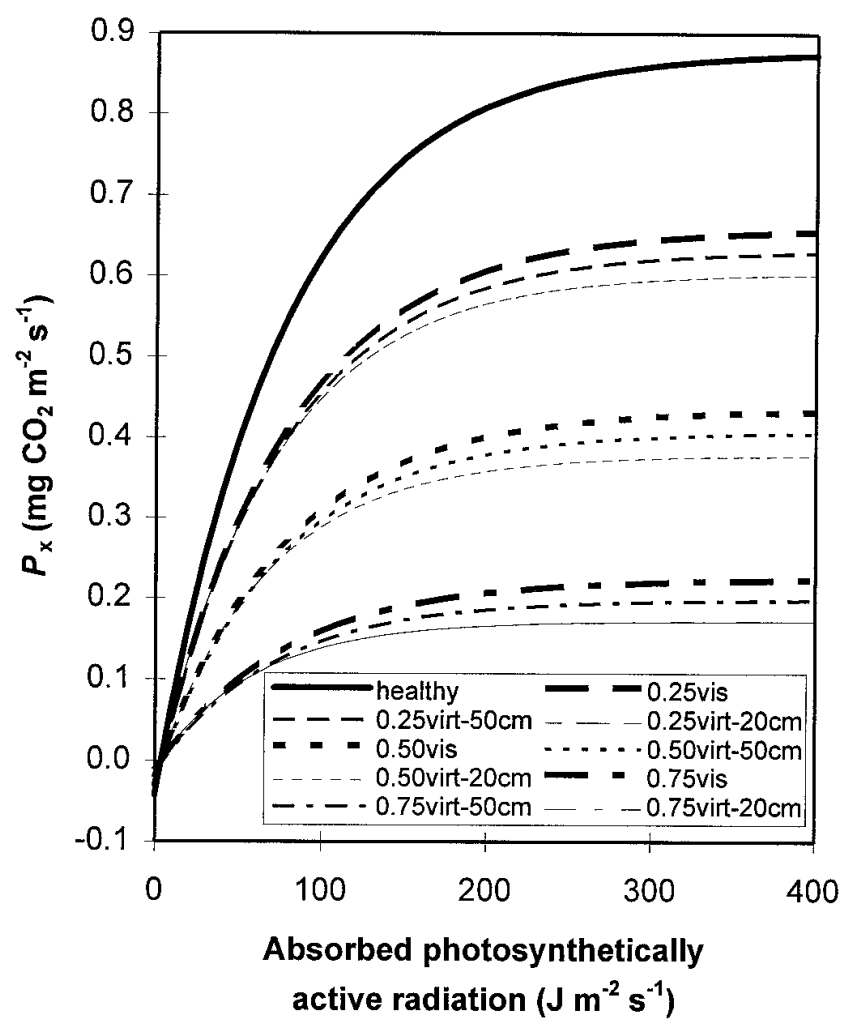

Fig. 7. Photosynthesis light-response curves for visible (vis) and virtual (virt) severities computed for gross leaf photosynthesis rate $\left(P_{\max }\right)\left(9.22 \times 10^{-4} \mathrm{~g}\right.$ of $\left.\mathrm{CO}_{2} \mathrm{~m}^{-2} \mathrm{~s}^{-1}\right)$, dark respiration $\left(R_{d}\right)\left(4.28 \times 10^{-5} \mathrm{~g}\right.$ of $\left.\mathrm{CO}_{2} \mathrm{~m}^{-2} \mathrm{~s}^{-1}\right)$, and initial light use efficiency $(\varepsilon)\left(1.19 \times 10^{-5} \mathrm{~g}^{\circ} \mathrm{CO}_{2} \mathrm{~J}^{-1}\right)$, for leaf lengths of 50 and $20 \mathrm{~cm}$ long and with visible BB severities of $0.25,0.50$, and 0.75 , respectively. growth models that focus on light interception, rather than on photosynthesis (24).

The independence of the lengths of visible lesion and virtual lesion extension for the three photosynthesis parameters is essential to our model. $L_{v e}$ values of 1.1 and $-3.9 \mathrm{~cm}$, respectively, for $P_{\max }$ and $R_{d}$ indicate that effects on $P_{\max }$ and $R_{d}$ are opposite and the latter relatively greater. The positive $L_{v e}$ value for $P_{\max }$ suggests that either the area that does not assimilate $\mathrm{CO}_{2}$ is larger than the visible lesion or the $\mathrm{CO}_{2}$-assimilation rate is decreased per unit of green area. The negative $L_{v e}$ value for $R_{d}$ suggests that either respiration occurs in the visible lesion or respiration rate per unit of green area is increased. The latter was confirmed by Watanabe and Asaumi (29) who measured a 1.7-fold increase in oxygen uptake per unit of leaf area after symptom appearance compared with healthy leaves. Assuming that $\mathrm{CO}_{2}$ assimilation and respiration do not occur in the visible lesion, our results indicate that in green leaf tissue of an infected leaf maximum photosynthesis rate is reduced, whereas respiration is increased.

Two error factors could not be removed entirely from the data analysis. We could not rule out the possibility that in certain cases virtual lesion extension extended beyond the photosynthesis measurement chamber, resulting in underestimation of $L_{v e}$. However, given the limited lengths of $L_{v e}$ for $P_{\max }$ and $R_{d}$, the error appears to be marginal. A second potential error factor is that bacterial inoculum concentrations were not determined, and different inoculum concentrations for the three measurement series may have caused minor differences in photosynthesis in cases of small lesions. Because bacteria continue to multiply while spreading through the xylem vessels $(9,17)$, it seems unlikely, however, that differences in inoculum concentration have an effect for larger lesions.

Virtual lesion extension represents a measure for summarizing the effects of diseases that spread as large lesions longitudinally over the leaf blade. The level of detail in the approach was designed to be commensurate with the aim of summarizing $\mathrm{CO}_{2}$-exchange effects at the whole-leaf level for application at the crop level. For this reason, approaches to describe lesion shape or spatial variation in $\mathrm{CO}_{2}$-exchange characteristics within a leaf were thought to contain more detail than necessary to capture the essence of the effects. The $\beta$ model was introduced originally for foliar diseases that spread two-dimensionally (2). In contrast, our results show that the effects of $\mathrm{BB}$ on rice leaf photosynthesis can be characterized by the one-dimensional length of the visible lesion plus virtual lesion extension. The measure does not reveal the physiological causes of the effects nor does it allow quantitative statements with regard to gradients of the parameters on the leaf. It has been postulated that the presence of bacteria in xylem vessels blocks water transport, affecting transpiration $(9,17)$ and leading to reduced photosynthetic rates. Because we did not measure transpiration rates, we could not test this hypothesis.

For diseases with significant virtual lesion extension, a specific degree of visible severity at the individual leaf level causes a decrease in total leaf photosynthesis that is smaller in longer leaves than in shorter leaves. However, because longer leaves may remain infectious for a longer period of time than shorter leaves and sturdiness of shorter leaves may reduce the rate of disease spread, the consequences of visible severity on disease epidemiology are ambiguous. Also, leaf architecture affects light penetration in the canopy, crop growth rate, and harvest index. Also, leaf length may affect the number of lesions per unit area, which is one of the factors that determines the impact of virtual lesion extension on crop photosynthesis. Therefore, the integrated effect of leaf length on crop production is difficult to assess.

The effect of diseases on photosynthesis rate in green leaf tissue vary. Some diseases have no effect $(27,28)$, whereas others do $(2,25)$, implying that each plant-disease combination has to be assessed separately. However, analytical tools that summarize effects should have general applicability. Our generic concept of virtual lesion extension provides a nonspecific measure for summarizing the ef- 
fects of foliar diseases that spread longitudinally as large lesions over the leaf blade on $\mathrm{CO}_{2}$-exchange parameters at the whole-leaf level. When careful photosynthesis measurements for a diseaseplant combination have led to quantification of virtual lesion lengths for each photosynthesis parameter, standard photosynthesis modules can be modified easily. In the case of BB, the simplified procedure used resulted in careful quantification of the reduction in photosynthesis rate, forming the basis of a crop-growth simulation model that accounts for the effects of $\mathrm{BB}$ on growth and production of rice that has been used to develop disease-management tactics (5).

\section{ACKNOWLEDGMENTS}

The research was part of the SARP Project, partly funded by the Netherlands Directorate of International Cooperation. P. S. Teng and T. W. Mew (IRRI) supported the research throughout. Much of the practical work was done by R. Galang and A. Rosales (IRRI) and W. Valkenburg (AB-DLO), and K. J. Kleef. Technical assistance and advice was provided by P. van Leeuwen, S. Pot, and J. Withagen (AB-DLO), E. G. Rubia (PhilRice), and P. R. Reddy (Central Rice Research Institute, Cuttack, India). M. A. Ruissen (Department of Phytopathology, Wageningen Agricultural University) was instrumental in reviving bacterial inoculum. We also thank the various reviewers of this manuscript.

\section{LITERATURE CITED}

1. Barton-Willis, P. A., Roberts, P. D., Guo, A., and Leach, J. E. 1989. Growth dynamics of Xanthomonas campestris pv. oryzae in leaves of rice differential cultivars. Phytopathology 79:573-578.

2. Bastiaans, L. 1991. Ratio between virtual and visual lesion size as a measure to describe reduction in leaf photosynthesis of rice due to leaf blast. Phytopathology 81:611-615.

3. Bastiaans, L., and Roumen, E. C. 1993. Effect on leaf photosynthetic rate by leaf blast for rice cultivars with different types and levels of resistance. Euphytica 66:81-87.

4. Dreccer, M. F., Slafer, G. A., and Rabbinge, R. 1998. Optimization of vertical distribution of canopy nitrogen: An alternative trait to increase yield potential in winter cereals. J. Crop Prod. 1:47-77.

5. Elings, A., Reddy, P. R., Marimuthu, T., Rossing, W. A. H., Jansen, M. J. W., and Teng, P. S. 1997. Rice bacterial leaf blight: Field experiments, systems analysis and damage coefficients. Field Crops Res. 51:113-131.

6. Goudriaan, J. 1982. Potential production processes. Pages 98-113 in: Simulation of Plant Growth and Crop Production. F. W. T. Penning de Vries and H. H. van Laar, eds. Simulation Monographs. Pudoc Scientific Publishers, Wageningen, Netherlands.

7. Guo, A., Reimers, P. J., and Leach, J. E. 1993. Effect of light on incompatible interactions between Xanthomonas oryzae pv. oryzae and rice. Physiol. Mol. Plant Pathol. 42:413-425.

8. Heong, K. L., and Rossing, W. A. H. 1993. Damage by stem borer, bacterial leaf blight and sheath blight in rice: Conceptual models. Pages 5560 in: Mechanisms of Damage by Stem Borer, Bacterial Leaf Blight and Sheath Blight and their Effects on Rice Yield. W. A. H. Rossing, E. G. Rubia, M. Keerati-kasikorn, and P. R. Reddy, eds. SARP Res. Proc. DLO Research Institute for Agrobiology and Soil Fertility and Department of Theoretical Production Ecology, Wageningen Agricultural University, Netherlands, and International Rice Research Institute, Los Baños, Philippines.

9. Horino, O., and Kaku, H. 1989. Defence mechanisms of rice against bacterial blight caused by Xanthomonas campestris pv. oryzae. Pages 135-152 in: Bacterial Blight of Rice, Proc. Int. Workshop Bacterial Blight Rice. S. J. Banta, E. Cervantes, and T. W. Mew, eds. International Rice Research Institute, Los Baños, Philippines.

10. Jin, K. S., Mew, T. W., and Dingkhun, M. 1993. The relationship between bacterial blight development and rice crop growth. RDA J. Agric. Sci. Crop Prot. 35:360-402.

11. Johnson, K. B. 1987. Defoliation, disease and growth: A reply. Phytopathology 77:1495-1497.
12. Justesen, S. H., and Tammes, P. L. M. 1960. Studies of yield losses. I. The self-limiting effect of injurious or competitive organisms on crop-yield. Tijdschr. Plantenziekten 66:281-287.

13. Kauffman, H. R., Reddy, A. P. K., Hsieh, S. P. Y., and Merca, S. D. 1973. An improved technique for evaluating resistance of rice varieties to Xanthomonas oryzae. Plant Dis. Rep. 57:537-541.

14. Khush, G. S., Mackill, D. J., and Sidhu, G. S. 1989. Breeding for resistance to bacterial blight. Pages 207-217 in: Bacterial Blight of Rice. Proc. Int. Workshop Bacterial Blight Rice. S. J. Banta, E. Cervantes, and T. W. Mew, eds. International Rice Research Institute, Los Baños, Philippines.

15. Kropff, M. J., van Laar, H. H., and Matthews, R. B., eds. 1994. ORYZA1, an ecophysiological model for irrigated rice production. SARP Res. Proc. DLO Research Institute for Agrobiology and Soil Fertility and Department of Theoretical Production Ecology, Wageningen Agricultural University, Netherlands, and International Rice Research Institute, Los Baños, Philippines.

16. Louwerse, W., and van Oorschot, J. L. P. 1969. An assembly for routine measurements of photosynthesis, respiration and transpiration of intact plants under controlled conditions. Photosynthetica 3:305-315.

17. Mew, T. W., Alvarez, A. M., Leach, J. E., and Swings, J. 1993. Focus on bacterial blight of rice. Plant Dis. 77:5-12.

18. Penning de Vries, F. W. T., van Keulen, H., and Alagos, J. C. 1990. Nitrogen redistribution and potential production in rice. Pages 513-520 in: Proc. Int. Congr. Plant Physiol. S. K. Sinha, P. V. Sane, S. C. Bhargava, and P. K. Aggarwal, eds. Vol. 1, InPrint Exclusives, S-402. Greater Kaillash-II, New Delhi.

19. Philip, R., and Devadath, S. 1981. Studies on the physiology of bacterial blight infected tolerant and susceptible rice cultivars. Phytopathol. Z. 101: 75-81.

20. Prioul, J.-L., Brangeon, J., and Reyss, A. 1980. Interaction between external and internal conditions in the development of photosynthetic features of a grass leaf. II. Reversibility of light-induced responses as a function of developmental stages. Plant Physiol. 66:770-774.

21. Rabbinge, R., Ward, S. A., and van Laar, H. H. 1989. Simulation and Systems Management in Crop Protection. Simulation Monographs. Pudoc Scientific Publishers, Wageningen, Netherlands.

22. Reddy, A. P. K., Katyal, J. C., Rouse, D. I., and MacKenzie, D. R. 1979. Relationship between nitrogen fertilization, bacterial leaf blight severity, and yield of rice. Phytopathology 69:970-973.

23. Reddy, A. P. K., and Kauffman, H. E. 1973. Multiplication and movement of Xanthomonas oryzae in susceptible and resistant hosts. Plant Dis. Rep. 57:784-787.

24. Rossing, W. A. H., van Oijen, M., van der Werf, W., Bastiaans, L., and Rabbinge, R. 1992. Modelling the effects of foliar pests and pathogens on light interception, photosynthesis, growth rate and yield of field crops. Pages 161-180 in: Pests and Pathogens: Plant Responses to Foliar Attack. P. G. Ayres, ed. Bios Scientific Publishers, Oxford.

25. van der Werf, W., Bastiaans, L., Rossing, W. A. H., and Rabbinge, R. 1991. Modeling crop response to growth reducing factors. Pages 87-102 in: Proc. Biotic Stress Barley Arid Semi-Arid Environ. Montana State University, Boseman, and International Center for Agricultural Research in Dry Areas, Aleppo, Syria.

26. van Keulen, H., and Seligman, N. G. 1987. Simulation of Water Use, Nitrogen Nutrition and Growth of a Spring Wheat Crop. Simulation Monographs. Pudoc Scientific Publishers, Wageningen, Netherlands

27. van Oijen, M. 1991. Photosynthesis is not impaired in healthy tissue of blighted potato plants. Neth. J. Plant Pathol. 96:55-63.

28. Waggoner, P. E., and Berger, R. D. 1987. Defoliation, disease, and growth. Phytopathology 77:393-398.

29. Watanabe, M., and Asaumi, T. 1975. Studies on the physiological changes in the rice plants infected with Xanthomonas oryzae pv. oryzae. I. Relationship between the increase in respiratory rate and multiplication of the bacteria in the infected leaves. (In Japanese, with English summary) Ann. Phytopathol. Soc. Jpn. 41:364-372.

30. Watanabe, M. S., Samejima, S., and Hosawaka, D. 1980. Studies on the physiological changes in the rice plants infected with Xanthomonas oryzae pv. oryzae. III. Accumulation of ${ }^{14} \mathrm{C}$-photosynthetic assimilates in the lesions. (In Japanese, with English summary) Ann. Phytopathol. Soc. Jpn. 46:623-627. 